\title{
An Extension of the Theory of Planned Behaviour to Predict Willingness to Pay for the Conservation of Urban Lakes for Mitigating the Urban Heat Island Effect
}

\author{
Li Zhang*, Hiroatsu Fukuda \\ Department of Architecture, University of Kitakyushu, Kitakyushu, Japan \\ Email address: \\ Zhangli04865@gmail.com (Li Zhang) \\ ${ }^{*}$ Corresponding author
}

To cite this article:

Li Zhang, Hiroatsu Fukuda. An Extension of the Theory of Planned Behaviour to Predict Willingness to Pay for the Conservation of Urban Lakes for Mitigating the Urban Heat Island Effect. Journal of Energy and Natural Resources. Vol. 8, No. 2, 2019, pp. 50-59. doi: $10.11648 /$ j.jenr.20190802.12

Received: March 24, 2019; Accepted: May 20, 2019; Published: May 23, 2019

\begin{abstract}
Urban heat island effect has become a serious environmental problem of Beijing and urban lakes are proved to be effective in mitigating this phenomenon. Urban lakes are proved to be effective in mitigating urban heat island effect, while this effect has long been overlooked. One important reason is that its economic value cannot be easily measured. This paper empirically investigates the Beijing residents' willingness of pay for the benefit of urban lakes in mitigating the urban heat island effects. In addition, the government also willing to promote public participation in environmental issues. To explore the influencing factors of residents' willingness to pay, this study applied an extended framework of the theory of planned behavior by introducing the concept of environmental concern. The estimated mean willingness to pay was 24.44 US dollars per year. In order to improve the prediction power of respondents' pro-environmental behavior, the original framework of the Theory of Planned behavior were extended by adding the factor of environmental concern. The new relation of components show that environmental concern influence respondents' willingness to pay both directly and indirectly, and the explanatory power of the original prediction model is improved. This research reveal that a majority of residents in Beijing are willing to contribute for the conservation of urban lakes for mitigating urban heat island effect, while environment related information disclosure is necessary for promoting public participation in urban environment management.
\end{abstract}

Keywords: Three Willingness to Pay, Theory of Planned Behavior, Urban Lake, Environmental Concern, Urban Heat Island

\section{Introduction}

In the past 40 years, China's population dwelling in urban area rate has risen from $17.9 \%$ to more than $57.35 \%$ [1]. Rapid urbanization has brought significant changes in the urban climate [2]. Urban heat island (UHI) effect is one of the most concerned urban environmental problems. UHI effect, which is, the phenomenon of a significant difference between urban and suburban temperature [3]. This phenomenon is mainly caused by anthropogenic heat release, change in geometry as well as the introduction of new material. UHI effect reduces the thermal comfort of urban residents, improves energy consumption in summer and exacerbates the deterioration of air quality [4-7].
Beijing, the capital of China, has experienced rapid urban expansion during the past few decades and its UHI effect is significant. The study of Cui, et al. [8] has shown that the urban-suburban temperature difference in Beijing can be up to 8 degrees in winter. UHI effect has become one of the main urban environmental problems posed to Beijing citizens.

Water bodies, as one of the important part of the urban ecosystem, were proved to be effective in mitigating the UHI effect. Lai, et al. [9] compared different methods to alleviate the UHI effect, the results show that the urban water body can reduce the temperature of the surrounding area up to $1.8 \mathrm{~K}$. 
The study of Manteghi, et al. [10] has shown that urban lakes can reduce peripheral temperatures by up to $1-2^{\circ} \mathrm{C}$. The study of Imam Syafii, et al. [11] indicated that if the pond in the city is parallel to the dominant wind direction in the city, then the surrounding average temperature can be reduced by up to $1.6^{\circ} \mathrm{C}$ in summer. Sun and Chen [12] studied 197 urban water bodies in Beijing, with the result that urban water bodies can reduce the ambient air temperature by an average of $0.54^{\circ} \mathrm{C}$, while the effect is related to the location, shape, size, and surrounding constructions.

The effect of the urban water bodies on mitigating UHI effect has been reported by numbers of studies, but its role in urban climate control has not be put enough attention, one of the main reasons is that its economic value cannot be easily evaluated.

The value of urban lakes in mitigating urban heat island is defined as "non-market" value, which cannot be direct measured through market behavior. The economic value of this kind of environmental goods can only be assessed through non-market valuation techniques [13].

In this study, the contingent valuation method (CVM), a widely used non-market value evaluation method was applied to assess residents' willingness to pay (WTP) for the conservation of urban lakes for UHI effect mitigation. Contingent valuation method belongs to the family of stated preference method, which obtains the WTP for an environmental goods by directly asking questions to the respondents [14]. It is one of the most widely used non-market value evaluation method.

In addition, according to China's agenda 21 [15], residents are encouraged to participate in the urban sustainable development, while residents' pro-environmental behavior has not been fully discovered due to the long-term top-down governance model and other reasons. This study attempts to explore the factors that affect residents ' WTP for UHI effect management.

At first, the study with regard to the nature of pro-environment behavior was limited to socio-economic factors such as education, gender, age, income, etc. [16, 17]. However, these social structural variables have been criticized for only explain the modest variances in measures of environmental behavioral intention and behavior [18]. Then researchers have turned to focus on psycho-social constructs, such as attitude, subjective norm, and belief, research shows that these factors can better predict people's pro-environmental behavior [19, 20]. The common feature of these researches is that they are all based on the idea that people's behavior is influenced by their thoughts and feelings about the environment and pro-environment behavior. The most popular approach in this kind of research is the theory of planned behavior (TPB), which was introduced and developed by Ajzen in 1991. It reflects that individual's attitude, subjective norms, and perceived resources with regard to a specific behavior can help us better understand pro-environmental behaviors [21].

Although many studies support the original TPB in predicting people's pro-environmental intentions and behaviors, others point out that there is still a considerable percentage of variance that does not explain one's intention and behavior. As a result, many studies have introduced extended TPB model to increase its explanatory power. It has been suggested that exploring the impact of environmental concerns could improve the understanding of people's pro-environment intention and behaviors, which have not be taken into consideration in the original TPB model [22-24]. For these reasons, a variable (environmental concern) were added on the basis of the original TPB model to explore the intention and behavior characteristics of people in supporting UHI effect mitigation.

The environmental goods in this study are 15 urban lakes with an area of more than $3 \mathrm{hm}^{2}$ in the central area of Beijing (within five rings road). This paper aim to assess people's WTP for these urban lakes for their UHI mitigation effects, and to identify the underlying motivation. These information will be of great significance to policymakers for their investment on UHI management and promoting public participation in urban environmental governance.

This paper is different from the previous researches from two aspects. First, this paper expands the original TPB model, studies their relationships with the components of original TPB model, and explores its relationship to the motivation of pro-environmental behavior. Second, there are many studies that applied the extended TPB model in order to explain people's behavioral intention for improving the urban environment. For example, Lopez-Mosquera, et al. [25] focus on the WTP for the protection of urban parks, Zahedi, Batista-Foguet and van Wunnik [23] analyzes residents' WTP for reducing air pollution and greenhouse gases generated by private road traffic, Spash, Urama, Burton, Kenyon, Shannon and Hill [19] analyzes people's WTP for improving the ecological diversity in the water system, Wang, et al. [26] analysis of people's WTP for the protection of African elephants. To the best of our knowledge, studies with regard to the WTP for conserving urban water bodies in order to alleviate the UHI effect is limited, and no studies have used the extended TPB to explore the influencing factors for the payment.

The organization of this paper is as follows: In Section 2, the theoretical framework is presented, Section 3 presents the research method, Section 4 contains research results along with discussion, and Section 5 summarizes the main conclusions.

\section{Research method}

\subsection{Environmental Goods to Be Evaluated}

The total area of the urban lake within the 5th ring road of Bejing city is about $716.17 \mathrm{hm}^{2}$ (Figure 1). Among the total water surface, about $11 \mathrm{hm} 2$ is distributed within $2 \mathrm{nd}$ ring road, about $172.66 \mathrm{hm} 2$ is distributed in between 2 nd and 4 th ring roads, and about $354.4 \mathrm{hm} 2$ is distributed in between 4 th and 5th ring road [27]. The environmental goods of this study are the UHI mitigation effect of urban lakes of Beijing. 


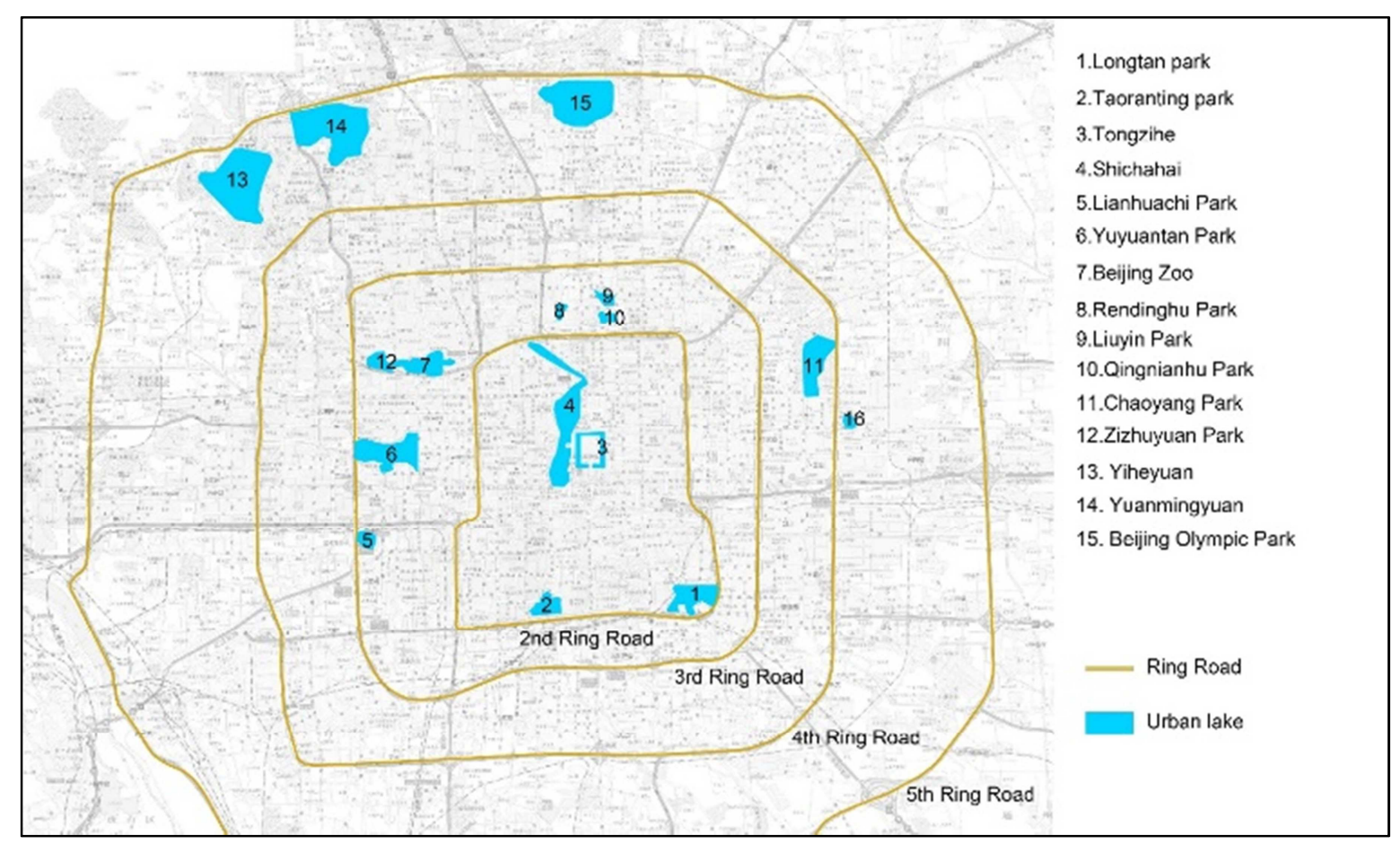

Figure 1. The distribution of urban lakes in Beijing.

\subsection{Online Survey}

Since the 1980s, the widespread of internet technology has made it possible to conduct relatively inexpensive and convenient questionnaires, which has also improved the efficiency and flexibility of questionnaire research. A large number of online-based stated preference researches with regard to social science and business began to emerge. In the early 1990s, not everyone has the opportunity to get access to the Internet since it was a relatively new technology, especially for the elderly. As a result, online questionnaires have long been accused of lack of representative and low response rate [28]. Since the beginning of the 21 st century, the number of Internet use has increased rapidly, and doubts about online questionnaires have begun to decrease. Ansolabehere and Schaffner [29] compared different questionnaire research method, pointing out that there are no significant differences between online questionnaire and conventional ones, [30].

According to the China Internet Development Report [31], By 2017, the number of Chinese netizens has reached 772 million, and the Internet penetration rate was $55.7 \%$. With the rapid development of network technology in China, more and more researchers have turned to choose online social platforms and online media for related researches [32].

The online questionnaire research of China began in 1995 [33]. Up to now, researches with online questionnaire have covered areas such as social behavior and psychology [34, 35], Consumer behavior [36], and environmental management [32].

Since the 21st century, a number of professional online questionnaire survey system have begun to appear and update continuously. The study was supported by Ranxing
Information Technology Co., Ltd., one of the leading online research organizations of China. During the research, invitation emails were distributed to 2.6 million registered members of this research institution randomly. Users who agree to receive the questionnaire interview will receive a certain monetary reward. The questionnaire organization will analyze the user's IP address and account to ensure the authenticity of the sample, and impose certain penalties on duplicate and false answers to ensure the reliability of samples.

\subsection{The Design of the Survey}

A pre-research was conducted before the main research, aiming to determine the acceptance of CVM research and bid range. The pre-research was conducted with the open-ended format, and about 100 respondents were interviewed in the pre-survey. The formal study began on February 9, 2019, and lasted for 12 days. The online questionnaire was randomly distributed to Beijing citizens, and the final valid samples were 1055 .

A large number of studies indicated that WTP elicitation method could greatly affect people's WTP [37]. The dichotomous choice format was selected to be the WTP elicitation method. The advantage of the dichotomous choice format is that it can help respondents go through a complete evaluation process. Moreover, as an incentive-compatible elicitation method, it can prevent strategical bias [14]. As for payment vehicle, Carson, Flores and Meade [13] pointed out that the payment vehicle should have some relationship with the goods to be valued, and respondents should be familiar to the payment vehicle. Taxation was applied in this research for it is a mandatory payment method, which could reduce the risk 
of free riding and over pledging of respondents [13]. Compared with other kinds of taxations, Beijing citizens are more familiar with personal income tax, which is the reason income tax was chosen as the payment vehicle. As for the frequency of payment, according to the study of Egan, et al. [38], the payment frequency of this study is annual.

Before the questionnaire, each respondent was provided with information with regard to the purpose of the study, the distribution of urban lakes in Beijing, the effect of urban lakes in UHI effect mitigation, the hazards of UHI effect, and related rights of respondents within the survey. The questionnaire consists of three parts, the first part contains the respondents' socio-economic characteristic, the second part elicits respondents' WTP for conserving the urban lakes for the effect of UHI effect mitigation. The WTP question is: If the Beijing municipal government needs funding for conserving the urban lakes within 5 ring roads of Beijing to alleviating the UHI effect, based on your personal experience and the information mentioned above, considering your households' actual annual income, are your household willing to pay_Chinese Yuan (CHY) annually through increasing the personal income tax? Four bid values: $50 \mathrm{CHY}, 100 \mathrm{CHY}, 200$ $\mathrm{CHY}$, and $500 \mathrm{CHY}$ were randomly assigned to all of the respondents. These four bid values were decided according to the result of pre-research. The third part refers to the attitudinal profile of respondents' pro-environment behavior with regard to payment for UHI effect mitigation on 7 point Likert scales ( $1=$ strongly disagree, $7=$ strongly agree $)$.

\subsection{Data Analysis}

\subsubsection{Estimation of WTP}

In this research, the contingent valuation method was applied to calculate the WTP to conserve urban lakes for alleviating the UHI effect. The dichotomous choice format was used to elicit residents' WTP. The mean WTP was calculated based on the formulation provided by Hanley [39].

Mean WTP $=\int_{0}^{T}\left[1-G_{W T P}\right] d W$

$\mathrm{G}_{\mathrm{WTP}}$ is the distribution function of WTP. T is infinite for the true intention to pay and is truncated at some value for the purpose of estimation.

\subsubsection{Structural and Measurement Model}

This study applied the structural equation model to calculate the psycho-social factors that affecting WTP. In this study, AMOS 24.0 was used to process the data and SPSS 24.0 was used for descriptive analysis. Following the suggestion of Anderson and Gerbing [40], this study employed Confirmatory factor analysis (CFA) to assess measurement quality of the model, and used structural equation modeling (SEM) to verify the hypothetical conceptual model. As for the results of the CFA test, the robustness of mean squared error approximation (RMSEA) is expected to be located in between 0.05 and 0.08 . Comparative fit index (CFI), normed fit index (NFI), and goodness fit index (GFI) should be close to 0.9 or 1 . Finally, the Sobel test and bootstrapping method are used to calculate the indirect effect.

\section{Theoretical Framework and Hypothesis}

TPB is designed to predict and explain an individual's behavior in specific situations [21], Researchers agree that if people believe that their actions will lead to specific outcomes, if their important relatives (family, friends, relatives, colleagues, etc.) will support their behavior, and if people think they have the resources and the ability to perform a certain behavior, people will tend to conduct specific behavior.

TPB is an extension of the theory of reasoned action [41]. Theory of reasoned action is considered to be effective only in the context that people's behavior is under volitional control, while most human behavior is controlled by some non-volitional factors [42-44]. TPB expanded the boundaries of the theory of reasoned action, introduces some variables that are not related to volitional factors, and compensates for the shortcomings of the theory of reasoned action in the context of non-volitional control. As indicated by the original TPB theory, the most proximal predictor of people's behavior is the behavioral intention, and the behavioral intention is affected by the following three: 1) attitudes: people's positive or negative evaluation of a certain behavioral option. 2) Subjective norms: perceived pressure from related social group 3) Perceived behavior controls: perceived ease or difficulty in performing a behavior. A more positive attitude, a more positive social norm, and a stronger perceived behavioral control can enhance people's intention of conducting specific behavior [45].

The original TPB model has been widely used in environmental research to analyze various behavioral intentions and behaviors, such as participating in environmental activities [46], conserving the forest [47], protecting wild animals [26], and consuming urban environmental goods [19, 25, 48].

According to the original TPB model, if the respondent holds a positive attitude on the behavioral option, if the respondent's family and friends support his behavior, and if the respondent believes he/she has the ability to participate in the activities of protecting urban lakes to alleviate the UHI effect, he/she is more likely to fund environmental goods. Based on the above discussion, the following assumptions were proposed:

H1: If attitude towards conserving urban lake for alleviating the UHI effect is more positive, people's WTP would increase.

$\mathrm{H} 2$ : If subjective norms regarding conserving urban lake for alleviating the UHI effect is more positive, people's WTP would increase.

H3: If perceived behavioral control for conserving urban lake for alleviating UHI effects increase, people's WTP would increase.

Few studies have explored the potential relationship between attitude, perceived behavioral control, and subjective norm [49, 50]. People will take social norm into consideration when forming their attitudes and perceived 
resource for a specific behavioral option. So the following assumptions were proposed:

H4: If subjective norms regarding conserving urban lake for alleviating the heat island effect is more positive, people's attitude towards the behavioral option is more positive.

H5: If subjective norms regarding conserving urban lake for alleviating the heat island effect is more positive, people's perceived behavioral control towards the behavioral option increases.

In spite of that many studies have pointed out that the original theoretical framework of behavioral planning can be useful for predicting people's behavioral intentions and behaviors towards environmental protection, a considerable number of studies, however, indicated that a substantial percentage of variance was left with no explanation in intention and behavior [21, 51]. For this reason, many studies have proposed an extended version of the TPB model by adding new variables, aiming to enhance its explanatory power [52-54]. Among these variables, some researches focuses on the status of environmental concerns in predicting behavioral intentions [16, 54-56].

Environmental concerns are defined as the extent of individuals to aware of environmental issues and their willingness to solve environmental issues. A large number of studies have shown that environmental concerns play an important role in predicting people's environmental intentions and behaviors $[16,55,57,58]$. In addition, the study of Zahedi, Batista-Foguet and van Wunnik [23] shows that environmental concerns are positively related with three main factors of the TPB model: attitudes, perceived behavioral control, and subjective norms, and the study of Kollmuss and Agyeman [59] indicates that environmental concerns may affect people's environmental intentions and behaviors in an indirect way other than direct way by affecting relevant variables. Based on these discussions, the following hypothesis were proposed: Environmental concerns are positively related to people's attention to paying for UHI effect management. The following assumptions were proposed:

H6: Environmental concern is positively related to people's attitudes toward UHI effect management.

H7: Environmental concern is positively related to the subjective norms of paying for UHI effect management.

H8: Environmental concern is positively related to the perceived behavioral control towards UHI effect management.

H9: If Environmental concern is more positive, people's WTP would increase.

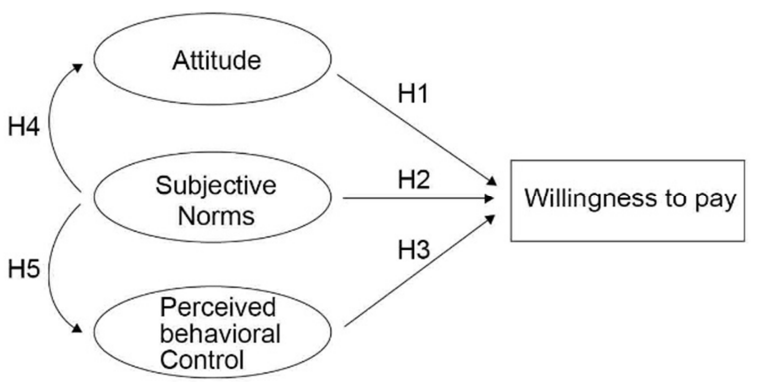

Figure 2. Initial TPB model for WTP. Squares represents observed variables, circles represents latent constructs.

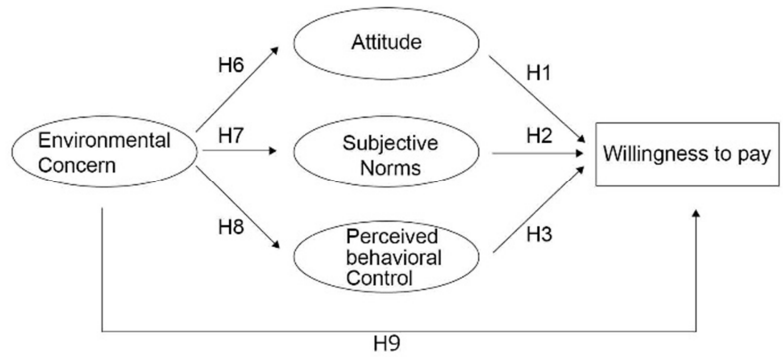

Figure 3. Expanded TPB model for WTP. Squares represents observed variables, circles represents latent constructs.

In addition, $\mathrm{H} 9$ environmental concern may affect WTP through attitude, subjective norm, and perceived behavior control, the assumptions are:

H10: environmental concern affect WTP through attitude

H11: environmental concern affect WTP through subjective norm

H12: environmental concern affect WTP through perceived behavior control

\section{Results and Discussion}

\subsection{WTP Analysis}

The distribution of WTP for different bids is presented in Table 1. As the bid value increases, the proportion of positive responses decreases gradually. Among the zero response samples, a total of 276 respondents refused to pay because they thought "it is the government's responsibility" and" do not believe the proper use of environmental fund". These samples were defined as "protest responses". Respondents who chose the option such as "I don't have the ability to pay for the fund" and "I don't think the UHI mitigation effect worth that much" is considered to be "real zero responses" (Figure 4). Only "real zero responses" were included when processing the data. The mean annual WTP for conserving urban lake for UHI effect mitigation is calculated to be 162.97 CHY (23.79 US dollars). Respondents with higher incomes are more likely to pay $(\beta=0.53, \mathrm{P}<0.01)$.

Table 1. Distribution of WTP responses.

\begin{tabular}{|c|c|c|c|c|c|}
\hline WTP & 50 & 100 & 200.0 & 500.0 & TOTAL \\
\hline Positive & $183(69.8 \%)$ & $184(70.2 \%)$ & $142(54.0 \%)$ & $142(53.0 \%)$ & $651(61.7 \%)$ \\
\hline Negative & $20(7.6 \%)$ & $21(8.0 \%)$ & $45(17.1 \%)$ & $42(15.7 \%)$ & $128(12.1 \%)$ \\
\hline Protest zero & $59(22.5 \%)$ & $57(21.8 \%)$ & $76(29.9 \%)$ & $84(31.3 \%)$ & $276(23.9 \%)$ \\
\hline Total & $262(100 \%)$ & $262(100 \%)$ & $263(100 \%)$ & $268(100 \%)$ & $1055(100 \%)$ \\
\hline
\end{tabular}




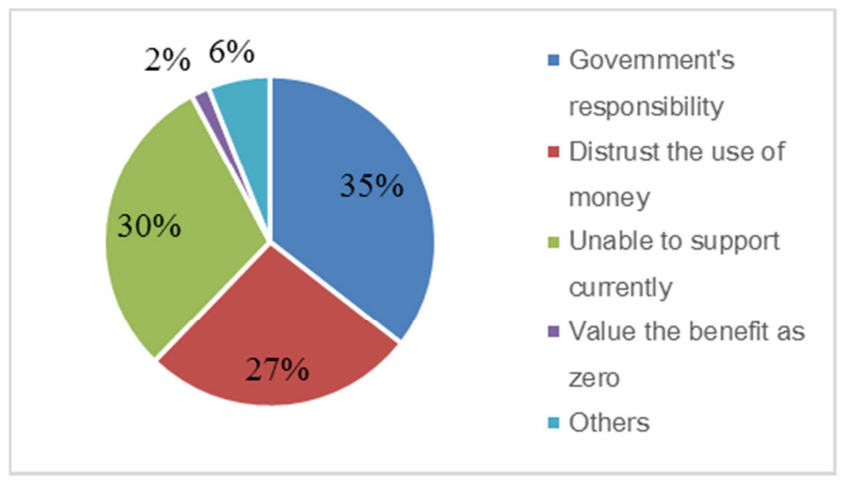

Figure 4. Motivation for zero responses

\subsection{Measurement Models}

Firstly the CFA on the original TPB model was conducted, including components such as attitude, subjective norm, and perceived behavior control (Table 2). The results showed that the model fits the data well (Chi -square $=251.9, \mathrm{GFI}=0.943$, $\mathrm{CFI}=0.964, \mathrm{NFI}=0.958$, RMSEA $=0.08$ ). Then all the four components were included (attitude, subjective norm, perceived behavior control, environmental concern) and tested. In general, it exhibited good psychometric properties. All standard regression coefficients were statistically significant in 0.01 level. In addition, all the scales satisfied the internal consistency.

Table 2. Reliability and CFA for the extended TPB model.

\begin{tabular}{|c|c|c|c|c|}
\hline Scales & Mean (s.d.) & $\boldsymbol{\beta}$ & $\mathbf{C R}$ & AVE \\
\hline Attitude $(\alpha=0.89)$ & & & 0.89 & 0.73 \\
\hline I think paying for conserving urban lakes is very positive & $5.35(1.58)$ & 0.85 & & \\
\hline I think paying for conserving urban lakes is responsible & $5.46(1.60)$ & 0.86 & & \\
\hline I think paying for conserving urban lakes is ecological & $5.54(1.55)$ & 0.85 & & \\
\hline Subjective $\operatorname{norm}(\alpha=0.90)$ & & & 0.9 & 0.74 \\
\hline I think people who are important to me will pay for conserving urban lakes & $4.73(1.67)$ & 0.85 & & \\
\hline I think people who are important to me will support the action of paying for urban lakes conservation & $4.91(1.69)$ & 0.89 & & \\
\hline I think people who are important to me will support me paying for urban lakes conservation & $5(1.67)$ & 0.84 & & \\
\hline Perceived behavioral control $(0.84)$ & & & 0.84 & 0.64 \\
\hline I think my payment will improve the urban environment & $5.17(1.66)$ & 0.75 & & \\
\hline It is not difficult for me to pay for urban lakes conservation & $4.62(1.93)$ & 0.79 & & \\
\hline I think I have time, money, and resources to pay for urban lakes conservation & $4.63(1.80)$ & 0.85 & & \\
\hline Environmental concern $(0.71)$ & & & 0.71 & 0.55 \\
\hline I care about urban environmental issues very much & $5.47(1.61)$ & 0.76 & & \\
\hline I think I will reduce other expenses for urban environment improvement & $4.79(1.76)$ & 0.72 & & \\
\hline
\end{tabular}

$\alpha$ reliability (Cronbach's alpha coefficient); $\beta$ (standard regression weight); s.d (Standard deviation); CR (composite reliability); AVE (average variance Extracted).

Finally, the scales' discriminant validity test was performed. According to Fornell and Larcker [60], if the squared correlations of different constructs are less than the AVE of each constructs, then the discriminant validity can be confirmed, as is shown in table 3 .

Table 3. The scales' discriminant validity.

\begin{tabular}{|c|c|c|c|c|}
\hline & Attitude & Subjective norm & Perceived behavior control & Environmental concern \\
\hline Attitude & 0.73 & & & \\
\hline Subjective norm & $0.50 * * *$ & 0.74 & & \\
\hline Perceived behavior control & $0.45 * * *$ & $0.5 * * *$ & 0.64 & \\
\hline Environmental concern & $0.4 * * *$ & $0.44 * * *$ & $0.44 * * *$ & 0.55 \\
\hline
\end{tabular}

$* * * \mathrm{p}<0.01$.

\subsection{Hypothesis testing}

The fitness of the initial model was acceptable (chi-square 249.1, RMSEA=0.08, GFI=0.943, CFI=0.958, NFI=0.90). Most of the structural coefficients are statistically significant $(p<0.01)$. According to the result, perceived behavior control is the only factor that affecting respondents' WTP $(\beta=0.600$, $\mathrm{p}<0.01)$. So $\mathrm{H} 3$ can be accepted, while $\mathrm{H} 1$ and $\mathrm{H} 2$ are rejected. At the same time, the influence of subjective norm on attitude $(\beta=0.769 p<0.01)$ and perceived behavior control $(\beta=0.692$ $\mathrm{p}<0.01)$ are confirmed, so $\mathrm{H} 4$ and $\mathrm{H} 5$ can be accepted. The initial model can explain $23.9 \%$ of the variance in WTP (Figure 5).

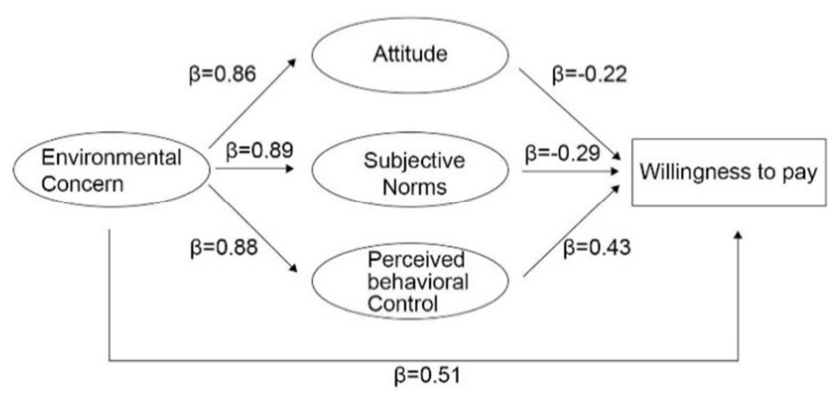

Figure 5. Initial TPB model for WTP. $\beta$ represents standard regression weight. 


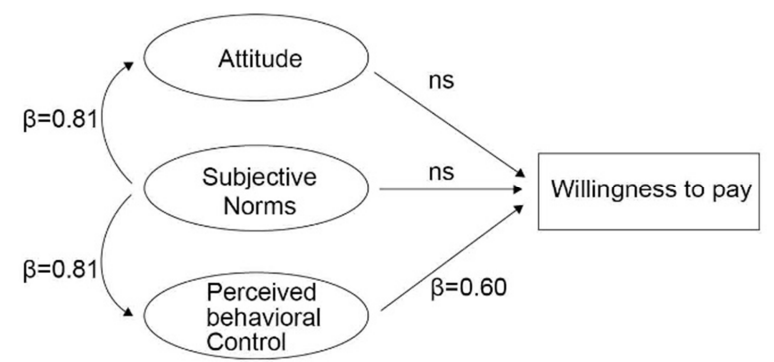

Figure 6. Extended TPB model for WTP. $\beta$ represents standard regression weight.

The fitness of the expanded structural model can be accepted (chi-square 291.7, RMSEA=0.08 GFI=0943, $\mathrm{CFI}=0.964, \mathrm{NFI}=0.958)$, most of the structural coefficients are significant $(\mathrm{p}<0.01)$. Environmental concern appears to have the greatest effect on WTP $(\beta=0.508 \mathrm{P}<0.1)$, followed with perceived behavior control $(\beta=0.428 \mathrm{p}<0.01)$, so confirming H3 and H9. The relationship of environmental concern and attitude $(\beta=0.861 \mathrm{p}<0.01)$, subjective norm $(\beta=0.893 \mathrm{p}<0.01)$, and perceived behavior control $(\beta=0.884 \mathrm{p}<0.01)$ can be confirmed, thus accepting $\mathrm{H} 6, \mathrm{H} 7$, and $\mathrm{H} 8$. The extended TPB model can explain $26.1 \%$ of the variance of WTP (Figure 6 ).

\subsection{Analysis of Mediation Effects}

The indirect effects between constructs were examined. In figure 3, attitude, subjective norm, and perceived behavior control mediate the effect between environmental concern and WTP. Table 4 lists the mediation effects of different mediator. The $p$-value of the Sobel test indicates that all indirect effects are significant. So we can conclude that attitude $(\beta=0.11$ $\mathrm{p}<0.01)$, subjective norm $(\beta=0.16 \mathrm{p}<0.01)$, and perceived behavior control $(\beta=0.47 \mathrm{p}<0.01)$ can significantly measure the relationship between environmental concern and WTP. Then H10, H11, and H12 can be confirmed (Table 4).

Table 4. Indirect effect.

\begin{tabular}{lllll}
\hline variable & Mediator & Dependent variable & value & se \\
\hline Environmental concern & attitude & WTP & 0.11 & 0.01 \\
Environmental concern & subjective norm & WTP & 0.16 & 0.01 \\
Environmental concern & perceived behavior control & WTP & 0 & 0.47 \\
\hline
\end{tabular}

\subsection{Further Discussion}

The TPB model, which was proposed by I. Ajzen, has been widely used in researches with regard to residents' WTP for environmental goods [21]. This study applied the TPB, for the first time, in predicting residents' WTP for UHI effect mitigation. Since a number of researches indicate that introducing additional constructs to the original TPB model, such as environmental concern, could effectively improve its explanatory power in specific $[52,56,61]$, this study estimated and compared the extended TPB model and conventional TPB model. The result has shown that the extended TPB model proposed in this research provides an effective model for predicting WTP for UHI effect mitigation.

The mean WTP indicated that Beijing households are willing to pay 162.97 CHY (23.79 US dollars) annually for urban lake conservation for UHI effect mitigation, which is consistent with the previous CVM study with regard to UHI mitigation [62]. According to the official data, the number of households in Beijing amounts to 5.38 million. If extended the mean WTP to the entire city, then the total WTP is 877 million. The WTP for UHI effect mitigation is strong among Beijing citizens.

It is worth noting that a total of $61.7 \%$ of respondents expressed their WTP for UHI effect mitigation, which lies within the ranges obtained in other online questionnaire survey, such as the study of Wang, Gong and Mao [26], where $53.36 \%$ of respondents were willing to pay, and Lei and Yang [32], where $70.1 \%$ of respondents were found willing to pay. Among those respondents who gave zero responses, about 276 respondents refused to pay because they thought "improving the urban environment is the responsibility of the government", and "the use of the environmental fund is questionable". These protest responses were excluded when processing the data. In addition, the socioeconomic characteristic of residents will also affect their WTP, respondents with higher income are more likely to give positive responses to WTP question.

The expanded model of planned behavior reveal the factors that influence the respondents' WTP for UHI mitigation. Firstly, residents' environmental concern was the strongest determinant for predicting respondents' WTP within regard to conserving urban lakes for UHI effect mitigation. The influence of environmental concern has been reported in a number of researches [23, 24], the general conclusion is that environmental concern is the fundamental factor which decides that whether respondents will behave in a pro-environmental way. In this case, it is found that environmental concern will affect the residents' WTP for conserving urban lakes both directly and indirectly, which is in line with previous studies $[16,54,56]$.

The next determinant that greatly influences respondents' WTP is perceived behavior control, which is also found in previous TPB studies $[19,63]$. Obviously, if residents thought they have the extra resources to contribute to the UHI mitigation, they will be more willing to consume the environmental goods. Therefore, it is necessary to strengthen the positive belief of those who already thought they are able to contribute for this issue, and change the negative belief of those who thought they do not have the corresponding resource currently.

Compared with the original TPB model, the extended TPB model that included environmental concern has improved the explanative power of WTP, from $23.9 \%$ to $26.1 \%$. As for the 
previous TPB studies, the squared multiple correlations of WTP is mostly in between $20 \%$ and $35 \%$ [64-66]. It is thus demonstrated that environmental concern contributes to a better explanation of Beijing residents' WTP for UHI mitigation.

Finally, what needs to be emphasized is that the research object of this study is the value of urban lakes in UHI effect mitigation. Therefore, the results cannot be generalized to all approaches that alleviate the UHI effect (urban green space, cool roof, permeable pavement).

\section{Conclusion}

The TPB model proposed by Ajzen [21] was adopted to predict Beijing residents' WTP for conserving urban lakes for UHI effect mitigation. This study provides an extended TPB model by employing the component of environmental concern. According to the experimental result, environmental concern and perceived behavior control significantly and positively affected respondents' WTP. In addition, environmental concern could influence people's pro-environmental behavior directly and indirectly. As is indicated by Wang, et al. [67], the increase in WTP depends on the combined effect of environmental concern and other factors of the extended TPB model. As for socio-economic determinants, residents' income positively correlated with WTP.

Urban managers and environmental activist should try to inform citizens about the causes, hazards of UHI effect along with its mitigation measures. Various media carriers: television, radio, and online media are all helpful in promoting environmental knowledge and pro-environmental behavior, thus increasing citizens' environmental concern. The enhancement of environmental concern will make people feel they have more resources for pro-environmental behavior, which could promote their participation in UHI effect mitigation. At the same time, residents' WTP various according to their income, policymaker may consider taping the potential source of money for UHI mitigation according to different income level.

Moreover, a large number of protest responses appeared within the questionnaire for respondents doubt the use of the environmental fund, it is necessary to disclose the use of environmental taxation and related information with regard to urban environmental management, which will also enhance public participation.

Concerning future research perspective: 1. Ajzen and Fishbein [68] pointed out that there is a gap between the intended WTP and the actual WTP, it is necessary to detect how these influencing factors proposed in this study affect the true WTP. 2. This study elicits the value of urban lakes in mitigating the UHI effect, the underlying assumption is that respondents have the ability to distinguish different values of urban lakes (leisure value, aesthetic value, and social value, et al.) within a hypothetical context, which has been criticized by related social-psycho research [69]. More discussion on this "value decomposition" issue is necessary. 3. There are cultural differences among territories. Comparing the influencing factors for supporting UHI mitigation within various cultural backgrounds worth further exploration.

\section{Acknowledgements}

We are grateful to Shiwen Quan (Chinese Academy of Social science, China) for his important suggestions on experiment design. The authors would like to express their gratitude to the editors and reviewers for their thoughtful comments and constructive suggestions on improving the quality of the paper.

\section{References}

[1] Y. Li, L. Jia, W. Wu, J. Yan, Y. Liu, Urbanization for rural sustainability - Rethinking China's urbanization strategy, Journal of Cleaner Production 178 (2018) 580-586.

[2] N. B. Grimm, S. H. Faeth, N. E. Golubiewski, C. L. Redman, J. Wu, X. Bai, J. M. Briggs, Global change and the ecology of cities, Science 319 (5864) (2008) 756-760.

[3] D. J. Unwin, The urban climate, H. E. Lansberg, Academic Press, Volume 28, International Geophysics Series, 1981, No. of pages: 275, International Journal of Climatology 2 (3) (2010) 302-303.

[4] T. Kjellstrom, D. Briggs, C. Freyberg, B. Lemke, M. Otto, O. Hyatt, Heat, Human Performance, and Occupational Health: A Key Issue for the Assessment of Global Climate Change Impacts, Annual Review of Public Health 37 (37) (2016) 97.

[5] J. Rocklöv, B. Forsberg, K. Ebi, T. Bellander, Susceptibility to mortality related to temperature and heat and cold wave duration in the population of Stockholm County, Sweden, Global Health Action 7 (1) (2014) 22737.

[6] M. Stafoggia, F. Forastiere, D. Agostini, N. Caranci, F. De'Donato, M. Demaria, P. Michelozzi, R. Miglio, M. Rognoni, A. Russo,. Factors affecting in-hospital heat-related mortality: a multi-city case-crossover analysis, Journal of Epidemiology and Community Health (1979-) 62 (3) (2008) 209-215.

[7] X. Xu, J. E. González, S. Shen, S. Miao, J. Dou, Impacts of urbanization and air pollution on building energy demands Beijing case study, Applied Energy 225 (2018) 98-109.

[8] Y. Cui, D. Yan, T. Hong, J. Ma, Temporal and spatial characteristics of the urban heat island in Beijing and the impact on building design and energy performance, Energy 130 (2017) 286-297.

[9] D. Lai, W. Liu, T. Gan, K. Liu, Q. Chen, A review of mitigating strategies to improve the thermal environment and thermal comfort in urban outdoor spaces, The Science of the total environment 661 (2019) 337-353.

[10] G. Manteghi, H. Bin Limit, D. Remaz, Water bodies an urban microclimate: A review, Modern Applied Science 9(6) (2015) $1-12$.

[11] N. Imam Syafii, M. Ichinose, E. Kumakura, S. K. Jusuf, K. Chigusa, N. H. Wong, Thermal environment assessment around bodies of water in urban canyons: A scale model study, Sustainable Cities and Society 34 (2017) 79-89.

[12] R. Sun, L. Chen, How can urban water bodies be designed for climate adaptation?, Landscape and Urban Planning 105(1-2) (2012) 27-33 
[13] R. T. Carson, N. E. Flores, N. F. Meade, Contingent valuation: Controversies and evidence, Environmental and Resource Economics 19 (2) (2001) 173-210.

[14] R. T. Carson, W. M. Hanemann, Chapter 17 Contingent Valuation, in: K.-G. Mler, J. R. Vincent (Eds.), Handbook of Environmental Economics, Elsevier2005, pp. 821-936.

[15] D. o. P. C. o. China, China's Agenda 21, Environmental Science Press, Beijing, 1994.

[16] J. De Groot, L. Steg, General beliefs and the theory of planned behavior: The role of environmental concerns in the TPB, Journal of Applied Social Psychology 37 (8) (2007) $1817-1836$.

[17] B. Torgler, M. A. García-Valiñas, The determinants of individuals' attitudes towards preventing environmental damage, Ecological Economics 63 (2) (2007) 536-552.

[18] U. Sauer, A. Fischer, Willingness to pay, attitudes and fundamental values - On the cognitive context of public preferences for diversity in agricultural landscapes, Ecological Economics 70 (1) (2011) 1-9.

[19] C. L. Spash, K. Urama, R. Burton, W. Kenyon, P. Shannon, G. Hill, Motives behind willingness to pay for improving biodiversity in a water ecosystem: Economics, ethics and social psychology, Ecological Economics 68 (4) (2009) 955-964.

[20] J. I. M. D. Groot, L. Steg, Relationships between value orientations, self-determined motivational types and pro-environmental behavioural intentions, Journal of Environmental Psychology 30 (4) (2010) 368-378.

[21] I. Ajzen, The theory of planned behavior, Organizational Behavior and Human Decision Processes 50 (2) (1991) 179-211.

[22] M. A. Vicente-Molina, A. Fernández-Sáinz, J. Izagirre-Olaizola, Environmental knowledge and other variables affecting pro-environmental behaviour: comparison of university students from emerging and advanced countries, Journal of Cleaner Production 61 (2013) 130-138.

[23] S. Zahedi, J. M. Batista-Foguet, L. van Wunnik, Exploring the public's willingness to reduce air pollution and greenhouse gas emissions from private road transport in Catalonia, The Science of the total environment 646 (2019) 850-861.

[24] Y. Kim, H. Han, Intention to pay conventional-hotel prices at a green hotel - a modification of the theory of planned behavior, Journal of Sustainable Tourism 18 (8) (2010) 997-1014.

[25] N. Lopez-Mosquera, T. Garcia, R. Barrena, An extension of the Theory of Planned Behavior to predict willingness to pay for the conservation of an urban park, Journal of environmental management 135 (2014) 91-9.

[26] Z. Wang, Y. Gong, X. Mao, Exploring the value of overseas biodiversity to Chinese netizens based on willingness to pay for the African elephants' protection, The Science of the total environment 637-638 (2018) 600-608.

[27] Y. Han, Inheritance and Development of Beijing Urban Water Landscape System, Proceedings of the China Urban Planning Annual Conference, 2015, 2015.

[28] G. Szolnoki, D. Hoffmann, Online, face-to-face and telephone surveys - Comparing different sampling methods in wine consumer research, Wine Economics \& Policy 2 (2) (2013)
57-66.

[29] S. Ansolabehere, B. F. Schaffner, Does Survey Mode Still Matter? Findings from a 2010 Multi-Mode Comparison, Political Analysis 22 (3) (2017) 285-303.

[30] M. D. Kaplowitz, T. D. Hadlock, R. Levine, A Comparison of Web and Mail Survey Response Rates, Public Opinion Quarterly 68(1) (2004) 94-101.

[31] C. A. o. China, China Internet Development Report, (2018).

[32] Z. Lei, W. Yang, Market segmentation and willingness to pay for green electricity among urban residents in China: The case of Jiangsu Province, Energy Policy 51 (4) (2012) 514-523.

[33] C. Wan, Network Survey System Analysis and Design, Beijing Jiaotong Univesity (2014).

[34] S. Y. Sun, A study of Consumer Information Search Online in China., Zhejiang University (2009).

[35] Z. Y. Cheng, Study on the Influence of Network Interaction on Purchase Intention and Trust Guarantee Mechanism in Social Network., Beijing University of Posts and Telecommunications (2013).

[36] J. X. Zha, The Relationship Between B2C E-commerce Customer Value and Customer's E-loyalty, Zhejiang University (2006).

[37] R. T. Carson, Contingent valuation: A user's guide, Environmental Science and Technology 34 (8) (2000) 1413-1418.

[38] K. J. Egan, J. R. Corrigan, D. F. Dwyer, Three reasons to use annual payments in contingent valuation surveys: Convergent validity, discount rates, and mental accounting, Journal of Environmental Economics and Management 72 (2015) 123-136.

[39] N. Hanley, J. F. Shogren, B. White, Environmental economics in theory and practice, 1997.

[40] J. C. Anderson, D. W. Gerbing, Structural Equation Modeling in Practice: A Review and Recommended Two-Step Approach, Psychological Bulletin 103 (3) (1988) 411-423.

[41] L. Lacaille, Theory of Reasoned Action, (2013).

[42] H. Han, L. T. Hsu, C. Sheu, Application of the Theory of Planned Behavior to green hotel choice: Testing the effect of environmental friendly activities, Tourism Management 31 (3) (2010) 325-334.

[43] K. Huchting, A. Lac, J. W. Labrie, An application of the Theory of Planned Behavior to sorority alcohol consumption, Addictive Behaviors 33 (4) (2008) 538-551.

[44] M. J. Lee, K. J. Back, Association members' meeting participation behaviors: development of meeting participation model, Journal of Travel \& Tourism Marketing 22 (2) (2007) 15-33.

[45] U. Liebe, P. Preisendörfer, J. Meyerhoff, To pay or not to pay: Competing theories to explain individuals' willingness to pay for public environmental goods, Environment and Behavior 43 (1) (2011) 106-130.

[46] K. S. Fielding, R. McDonald, W. R. Louis, Theory of planned behaviour, identity and intentions to engage in environmental activism, Journal of Environmental Psychology 28 (4) (2008) 318-326. 
[47] H. Karppinen, Forest owners' choice of reforestation method: an application of the theory of planned behavior, Forest Policy \& Economics 7 (3) (2005) 393-409.

[48] K. Bernath, A. Roschewitz, Recreational benefits of urban forests: explaining visitors' willingness to pay in the context of the theory of planned behavior, Journal of environmental management 89 (3) (2008) 155-66.

[49] V. A. Quintal, J. A. Lee, G. N. Soutar, Risk, uncertainty and the theory of planned behavior: A tourism example, Tourism Management 31(6) (2010) 797-805.

[50] A. Peters, H. Gutscher, R. W. Scholz, Psychological determinants of fuel consumption of purchased new cars, Transportation Research Part F Traffic Psychology \& Behaviour 14 (3) (2011) 229-239.

[51] F. G. Kaiser, A moral extension of the theory of planned behavior: Norms and anticipated feelings of regret in conservationism, Personality and Individual Differences 41 (1) (2006) 71-81.

[52] S. Bamberg, I. Ajzen, P. Schmidt, Choice of Travel Mode in the Theory of Planned Behavior: The Roles of Past Behavior, Habit, and Reasoned Action, Basic and Applied Social Psychology 25 (3) (2010) 175-187.

[53] Y. Heath, R. Gifford, Extending the theory of planned behavior: Predicting the use of public transportation, Journal of Applied Social Psychology 32 (10) (2002) 2154-2189.

[54] P. Hartmann, V. Apaolaza-Ibáñez, Consumer attitude and purchase intention toward green energy brands: The roles of psychological benefits and environmental concern, Journal of Business Research 65 (9) (2012) 1254-1263.

[55] S. Bamberg, How does environmental concern influence specific environmentally related behaviors? A new answer to an old question, Journal of Environmental Psychology 23 (1) (2003) 21-32.

[56] M.-F. Chen, P.-J. Tung, Developing an extended Theory of Planned Behavior model to predict consumers' intention to visit green hotels, International Journal of Hospitality Management 36 (2014) 221-230.

[57] R. J. Nawrotzki, The politics of environmental concern: A cross-national analysis, Organ Environ 25 (3) (2012) 286-307.

[58] M. F. Chen, P. J. Tung, Developing an extended Theory of Planned Behavior model to predict consumers' intention to visit green hotels, International Journal of Hospitality Management 36 (2014) 221-230.

[59] A. Kollmuss, J. Agyeman, Mind the Gap: Why do people act environmentally and what are the barriers to pro-environmental behavior?, Environmental Education Research 8 (3) (2010) 239-260.

[60] C. Fornell, D. F. Larcker, Evaluating Structural Equation Models with Unobservable Variables and Measurement Error, Journal of Marketing Research 18 (1) (1981) 39-50.

[61] D. L. Hoeksma, M. A. Gerritzen, A. M. Lokhorst, P. M. Poortvliet, An extended theory of planned behavior to predict consumers' willingness to buy mobile slaughter unit meat, Meat science 128 (2017) 15-23.

[62] L. Zhang, H. Fukuda, Z. Liu, Households' willingness to pay for green roof for mitigating heat island effects in Beijing (China), Building and Environment 150 (2019) 13-20.

[63] E. Pouta, M. Rekola, The theory of planned behavior in predicting willingness to pay for abatement of forest regeneration, Society and Natural Resources 14 (2) (2001) 93-106.

[64] B. Wang, C. Ren, X. Dong, B. Zhang, Z. Wang, Determinants shaping willingness towards on-line recycling behaviour: An empirical study of household e-waste recycling in China, Resources, Conservation and Recycling 143 (2019) 218-225.

[65] M. Sánchez, N. López-Mosquera, F. Lera-López, J. Faulin, An Extended Planned Behavior Model to Explain the Willingness to Pay to Reduce Noise Pollution in Road Transportation, Journal of Cleaner Production 177 (2018) 144-154.

[66] N. Lopez-Mosquera, M. Sanchez, Theory of Planned Behavior and the Value-Belief-Norm Theory explaining willingness to pay for a suburban park, Journal of environmental management 113 (2012) 251-62.

[67] S. Wang, J. Fan, D. Zhao, S. Yang, Y. Fu, Predicting consumers' intention to adopt hybrid electric vehicles: using an extended version of the theory of planned behavior model, Transportation 43 (1) (2016) 123-143.

[68] I. Ajzen, M. Fishbein, Understanding Attitudes and Predicting Social Behavior, 1980.

[69] R. S. Gregory, Valuing environmental policy options: A case study comparison of multiattribute and contingent valuation survey methods, Land Economics 76 (2) (2000) 151-173. 